\title{
Multifunctional Electronically Reconfigurable and Tunable Fractional-Order Filter
}

\author{
Jan Dvorak, Jan Jerabek, Zuzana Polesakova, David Kubanek, Petr Blazek \\ Department of Telecommunications, Faculty of Electrical Engineering and Communication, \\ Brno University of Technology, \\ Technicka 12, 61600, Brno, Czech Republic \\ dvorakjan@phd.feec.vutbr.cz
}

\begin{abstract}
In this paper the authors present a multifunctional reconfigurable fractional-order filter performing a low-pass, high-pass, band-pass and band-reject transfer function. The filter is based on two types of active elements, OTA (Operational Transconductance Amplifier) and ACA (Adjustable Current Amplifier). It provides pole frequency control, depending on the values of the transconductance of the OTA elements. The quality factor is also electronically controlled, depending on the amplification of the ACA element. The order of the filter can be changed by switching the fractional-order capacitor having various values of the order. The circuit was implemented as a PCB (Printed Circuit Board) and measured in laboratory conditions. Measurement results are compared with the simulation results. The behavioural models were used for the purpose of the simulation.
\end{abstract}

Index Terms-Fractional-order element; Analogue filter; Quality factor control; Pole frequency control; DACA; OTA.

\section{INTRODUCTION}

Fractional-order systems have become an interesting topic as they expand the possibilities of the integer-order electronic systems [1]-[8]. Analog systems are less limited than digital systems when it comes to the range of possible values or its possible settings. An integer order is usually given for the analogue circuits (filters, oscillators, generators...). Fractional-order systems can find use in biochemistry [6], [9], agriculture [9], control systems [9] and electronics [8], [10]-[15].

Fractional-order filters provide fine changing of the order in comparison with integer-order filters. The order of the fractional-order filters is given by $(n+\alpha)$, where $n$ is nonzero positive integer number and parameter $\alpha$ is a real number in range $0<\alpha<1$ [1], [4]. In point of view of the magnitude and phase responses, the fractional-order filters have magnitude slope of attenuation in stop-band region equal to $20(n+\alpha) \mathrm{dB} /$ decade. The phase shift is given by $90(n+\alpha)$ degrees [8], [12], [15].

Manuscript received 15 April, 2018; accepted 12 September, 2018.

This article is based upon work from COST Action CA15225, a network supported by COST (European Cooperation in Science and Technology). Research described in this paper was financed by Czech Science Foundation under grand no. 16-06175S and the National Sustainability Program under grant L01401. For the research, infrastructure of the SIX Center was used.
There are three possibilities how to create a fractionalorder circuit. The first possible way is to use a passive element with fractional-order character referred to as FOE (Fractional-Order Element) [16], capacitor in most cases, and use it as a dominant capacitor in filtration structure [1], [17], [18]. Though this solution may seem straightforward, there is no industrial manufacturing of FOE yet.

The second approach to the proposal of the fractionalorder filters is an approximation of a FOE using RC structure [1], [5], [11], [19]. There are several types of RC structures which can be used for approximation of the FOE. The most often used is an approximation by RC ladder structure [5], [11]. RC ladder is an option available for both modelling and measurement, which is an advantage. However, RC structure can only approximate a fractionalorder passive element in phase, magnitude and frequency range, making it a limited immitance [17]-[19]. A potential drawback of this method is the hardware form of the fractional-order RC ladder - a required change of alpha may require a change of hardware. This drawback may be fixed by using switched topology for example, however, switched device may bring in an interference and it also makes the circuit more complex.

The last method is an approximation of the fractionalorder transfer function by higher-integer-order filtering structure [4], [8], [12]-[14]. The higher-integer-order structure is obtained using approximation of a Laplacian term $\boldsymbol{s}^{\alpha}$ which is in a fractional-order transfer function replaced by the integer-order function. Most frequently, a second-order function is used [4]. On one hand, no manufactured or approximated fractional element is needed. On the other hand, to emulate a filter of a 1.5 order, originally a third-order filter is required for example [4], [7], [12]. Third-order filter is a more complex structure in comparison with a second-order filter. It may be seen as disadvantageous to create a complex structure and use it to underperform in terms of the filter order. The advantage of this method is that it is possible to use commercially available active elements with adjustable parameters and standard passive components.

The fractional-order filter containing these active elements allows the electronical controlling of the filter parameters (order, pole frequency, quality factor or passband gain for example). 
Table I summarizes some relevant previously reported works. The fractional-order low-pass filters without electronic controllable parameters are most commonly proposed [1], [4], [7], [15]. The electronic reconfiguration between two or more transfer functions, without topology modification and with electronically adjustable filter parameters, is presented only in the papers [8], [14]. However, none of the reported articles contains an electronically controlled quality factor.

In this paper, we present a reconfigurable fractional-order frequency filter with FOE which operates in the current mode. The filter provides electronic reconfigurability between Fractional Low-Pass Filter (FLPF), High-Pass Filter (FHPF), Band-Pass Filter (FBPF) and Band-Reject Filter (FBRF) transfer functions. The pole frequency and quality factor of the filter are controlled without disturbing each other by adjustable parameters of the used active elements. The second design option was chosen because it is effective, the parasitics do not devaluate the resulting circuit and the circuit complexity is sufficient. In this paper both simulations and experimental measurements are presented.

TABLE I. COMPARISON OF FEATURES OF THE RECENTLY INTRODUCED FRACTIONAL-ORDER FILTERS.

\begin{tabular}{|c|c|c|c|c|c|c|c|}
\hline 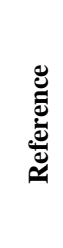 & 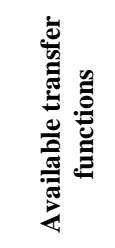 & 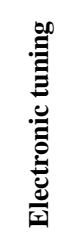 & 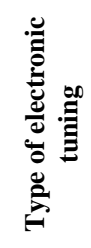 & 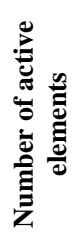 & 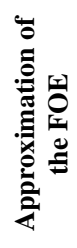 & 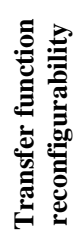 & 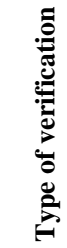 \\
\hline [1] & LP & No & - & 3 & Yes & No & Both \\
\hline [4] & $\begin{array}{c}\mathrm{LP}, \mathrm{HP}, \\
\text { BP }\end{array}$ & No & - & 2 & No & No & Both \\
\hline [7] & LP & No & - & 4 & No & No & Sim \\
\hline [8] & $\begin{array}{c}\mathrm{LP}, \mathrm{HP}, \\
\mathrm{BP}, \mathrm{BR}, \\
\mathrm{AP}\end{array}$ & Yes & $\begin{array}{c}f_{0}, \\
\text { order }\end{array}$ & 11 & No & Yes & Sim \\
\hline [11] & BP & No & - & 2 & Yes & No & Both \\
\hline [14] & $\begin{array}{l}\mathrm{LP}, \mathrm{HP}, \\
\mathrm{BP}, \mathrm{BR}\end{array}$ & Yes & order & 8 & No & Yes & Sim \\
\hline [15] & LP & No & - & 2 & Yes & No & Sim \\
\hline $\begin{array}{c}\text { Fig. } \\
2\end{array}$ & $\begin{array}{l}\text { LP, HP, } \\
\text { BP, BR }\end{array}$ & Yes & $f_{0}, Q$ & 6 & Yes & Yes & Both \\
\hline
\end{tabular}

\section{DESIGN OF THE CIRCUIT}

This section describes the design of the multifunctional electronically reconfigurable and tunable fractional-order frequency filter. The filter, originally with OTAs, ACAs and two capacitors is proposed based on using the FOE in the circuit structure instead of capacitor $C_{1} \quad\left(C_{2}\right.$ remains capacitor) as will be shown later.

The fractional-order capacitor is approximated using $\mathrm{RC}$ ladder structure which is shown in Fig. 1.

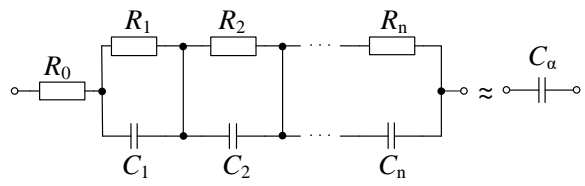

Fig. 1. The RC ladder structure used for approximation of the fractionalorder capacitor.

The values of the particular passive parts in the structure were computed in MATLAB using Oustaloup algorithm [19] for approximating the FOE with sufficient magnitude and phase accuracy in a specific frequency band. The FOE is approximated for use in the frequency band specified from $2 \mathrm{kHz}$ to $1 \mathrm{MHz}$ approximately.

The Butterworth-like approximation was used for design of the filter with maximally flat pass-band response [3], [4]. General transfer function of the LP filter is given by [3]

$$
T F_{1+\alpha}(s)=\frac{\omega_{0}^{1+\alpha} k_{1}}{s^{1+\alpha}+s^{\alpha} \omega_{0} k_{2}+\omega_{0}^{1+\alpha} k_{3}},
$$

where $\omega_{0}=2 \pi f_{0} \mathrm{rad} / \mathrm{s}$ and coefficients $k_{1}, k_{2}$ and $k_{3}$ are used to influence the shape of the obtained transfer function. The values of the coefficients $k_{1}, k_{2}$ and $k_{3}$ are adopted from [15]. Thanks to selection of these coefficients, quality factor of the filter can be tuned as is described in [15].

The proposed filter, which is depicted in Fig. 2, has been designed using three types of the active elements.

The first active element is Balanced-Output Transconductance Amplifier (BOTA) with current outputs. The function of the BOTA element is described as follows: $I_{\mathrm{OUT}+}=-I_{\mathrm{OUT}-}=g_{\mathrm{m}}\left(V_{\mathrm{IN}+}-V_{\mathrm{IN}-}\right)$, where the parameter $g_{\mathrm{m}}$ is electronically controllable transconductance.

Operation of Adjustable Current Amplifier (ACA) is described by the following equations: $I_{\mathrm{OUT}}=B I_{\mathrm{IN}}$, where parameter $B$ is controllable current gain of the ACA [20], [21]. If necessary, the number of the current outputs of the ACA active element can be easily expanded (as in case of ACA4 in Fig. 2, where there are two outputs, $I_{\mathrm{OUT}+}=$ $\left.-I_{\mathrm{OUT}-}=B I_{\mathrm{IN}}\right)$.

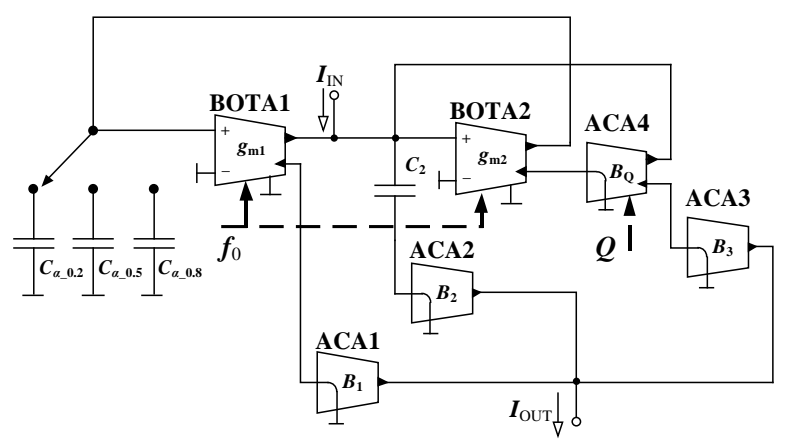

Fig. 2. Topology of the designed filter containing an approximated fractional-order capacitor (three variants).

The circuit presented in Fig. 2 contains the fractionalorder capacitor $C_{\alpha}$ (instead of $C_{1}$ ) and provides the following transfer function

$$
T F_{1+\alpha}(s)=\frac{s^{1+\alpha} B_{2}+s^{\alpha} B_{3} \frac{B_{Q} g_{m 2}}{C_{2}}+B_{1} \frac{g_{m 1} g_{m 2}}{C_{\alpha} C_{2}}}{s^{1+\alpha}+s^{\alpha} \frac{B_{Q} g_{m 2}}{C_{2}}+\frac{g_{m 1} g_{m 2}}{C_{\alpha} C_{2}}} .
$$

From the transfer function of the proposed filter (2) can be seen that filter provides LP, HP, BP and BR responses from one output by switching the current gains $B_{1}, B_{2}$ and $B_{3}$ of the ACA elements. The particular configurations of the transfer function of the designed filter are summarized in Table II. 
The designed filter offers ability to control its pole frequency $f_{0}$ by changing values of the transconductances. The circuit also possesses the quality factor $Q$ control by setting of value of the current gain $B_{\mathrm{Q}}$. The order of the filter is changed by switching the RC structures approximating the $C_{\alpha}$-s with different values of the $\alpha(0<\alpha<1)$.

TABLE II. CONFIGURATIONS OF THE TRANSFER FUNCTIONS.

\begin{tabular}{|c|c|c|c|}
\hline Transfer function & $\boldsymbol{B}_{\mathbf{1}}$ & $\boldsymbol{B}_{\mathbf{2}}$ & $\boldsymbol{B}_{\mathbf{3}}$ \\
\hline FLPF & 1 & 0 & 0 \\
\hline FHPF & 0 & 1 & 0 \\
\hline FBPF & 0 & 0 & 1 \\
\hline FBRF & 1 & 1 & 0 \\
\hline
\end{tabular}

The filter parameters can be computed by comparing the coefficients of denominators in (1) and (2):

$$
\begin{gathered}
g_{\mathrm{m} 1}=\frac{k_{3} \omega_{0}^{\alpha} C_{\alpha} B_{Q}}{k_{2}}, \\
g_{\mathrm{m} 2}=\frac{k_{2} \omega_{0} C_{2}}{B_{Q}} .
\end{gathered}
$$

From (3) and (4) the equation can be derived for pole frequency control

$$
\omega_{0}=\left(\frac{g \mathrm{~m} 1 g \mathrm{~m} 2}{C_{\alpha} C_{2} k_{3}}\right)^{\frac{1}{1+\alpha}} .
$$

\section{MEASUREMENT AND SiMULATION RESUlTS}

The features of the proposed fractional-order filter from Fig. 2 were verified by OrCAD PSpice simulations with behavioural models of the BOTA and ACA elements and also by experimental measurements.

The experimental measurements of the filter were performed with help of network analyser Agilent 4395A, using V/I, I/V converters and implemented filter in the Printed Circuit Board (PCB) form. The BOTA elements were replaced by one UCC N1B 0520 [22] chip with external resistors $(R)$ connected to $\mathrm{X}$ terminal representing a transconductance value $g_{\mathrm{m}}=1 / R$. The UCC N1B 0520 chip contains one Universal Current Conveyor (UCC) and one Second-generation Current Conveyor (CCII+/-). The dual-output ACA (ACA4 in filter topology) was implemented on PCB by DACA (Digitally Adjustable Current Amplifier) chip. The current gain $B$ of the DACA is controlled by 3-bit word in range from 1 to 8 with step 1 [20], [21]. Both these chips were developed at Department of Telecommunications of the Brno University of Technology in cooperation with ON Semiconductor. For implementation of the ACA elements were used the EL2082 chips [23]. Note that the current gain of the EL2082 chips is controlled using external DC voltage in range from 0 to $2.5 \mathrm{~V}$ [23].

The simulations and experimental measurement were performed with the following initial values of the filter parameters: pole frequency $f_{0}=10 \mathrm{kHz}$, quality factor $Q=$ 0.7 (current gain $\left.B_{\mathrm{Q}}=4\right)$, order of the filter $1.5(\alpha=0.5)$ and capacitors $C_{1}=6.8 \mathrm{nF}$ and $C_{2}=100 \mathrm{nF}$. The value of the fractional-order capacitor $C_{\alpha}$ is based on the chosen value of the $C_{1}$, parameter $\alpha$ and pole frequency $f_{0}$. The $C_{\alpha}$ is given by: $C_{\alpha}=C_{1} \omega_{0}{ }^{1-\alpha} \mathrm{Fs}^{\alpha-1}$. For above mentioned initial parameters is the value of the capacitor $C_{\alpha \_0.5}=1.7 \mu \mathrm{F} / \mathrm{s}^{0.5}$. The calculated values of the transconductances are: $g_{\mathrm{m} 1}=$ $1.89 \mathrm{mS}\left(R_{1}=1 / g_{\mathrm{m} 1}=531 \Omega\right)$ and $g_{\mathrm{m} 2}=1.44 \mathrm{mS}\left(R_{2}=\right.$ $\left.1 / g_{\mathrm{m} 2}=695 \Omega\right)$.

The magnitude responses of the FLPF, FHPF, FBRF and FBPF responses are demonstrated in Fig. 3. Results obtained by experimental measurement (solid lines) are compared with simulations results (dashed lines). From obtained responses it is obvious that measured results are very close to the simulations. The differences between results are mainly caused by current gain $B_{\mathrm{Q}}$, which is for DACA element slightly lower than the theoretical assumptions (for example for theoretic gain 4 is real current gain equal to 3.6), and by parasitic properties of the used active elements. That applies for all results presented below.

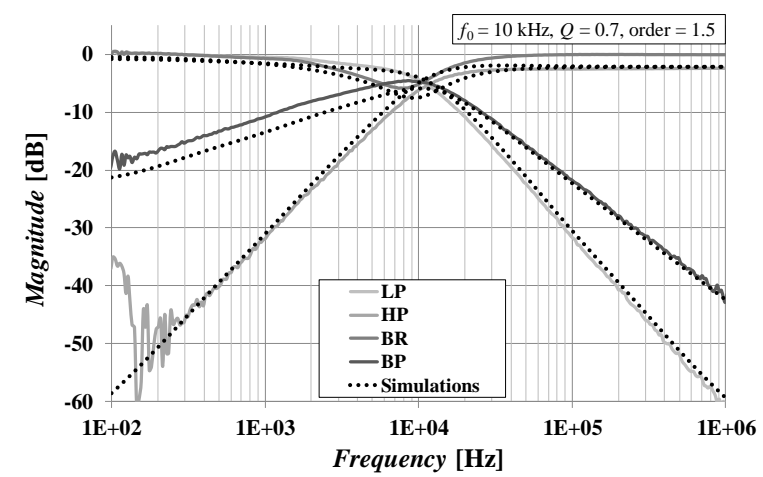

Fig. 3. Measurement results vs. simulations with behavioural models of the fractional-order multifunctional filter. Magnitude responses of FLPF, FHPF, FBRF and FBPF of the filter for $f_{0}=10 \mathrm{kHz}$, order 1.5 and $Q=0.7$.

Figure 4(a)-Fig. 4(b) demonstrate the magnitude and phase responses in case of changing the order of the FLPF, for three values of the order $(1.2,1.5$ and 1.8) when we choose the $f_{0}=50 \mathrm{kHz}$ and $Q=0.7$. The values of the passive elements are summarized in Table III. The obtained values of the slopes of attenuation from measured results are: $23.9 \mathrm{~dB} /$ decade (order 1.19), $30.4 \mathrm{~dB} /$ decade (order 1.52) and $35.7 \mathrm{~dB} /$ decade (order 1.79). The values of the slope of attenuation obtained from simulations are: $24.1 \mathrm{~dB} /$ decade (order 1.2), $30.1 \mathrm{~dB} /$ decade (order 1.5) and $36 \mathrm{~dB} /$ decade (order 1.8).

TABLE III. THE FILTER PARAMETERS FOR ORDER CHANGING.

\begin{tabular}{|c|c|c|c|}
\hline Theoretical values of the order & 1.2 & 1.5 & 1.8 \\
\hline $\boldsymbol{C}_{\boldsymbol{a}}\left[\boldsymbol{\mu} \mathbf{F s}^{\boldsymbol{\alpha} \cdot \mathbf{1}}\right]$ & 46.9 & 1.7 & 0.062 \\
\hline $\boldsymbol{C}_{\mathbf{2}}[\mathbf{n F}]$ & 10 & 10 & 10 \\
\hline $\boldsymbol{R}_{\boldsymbol{I}}=\mathbf{1} \boldsymbol{g}_{\boldsymbol{m} \boldsymbol{I}}[\boldsymbol{\Omega}]$ & 26 & 133 & 178 \\
\hline $\boldsymbol{R}_{\boldsymbol{2}}=\mathbf{1} \mathbf{g}_{\boldsymbol{m} \mathbf{2}}[\boldsymbol{\Omega}]$ & 878 & 174 & 130 \\
\hline
\end{tabular}

The differences at high frequencies (around $1 \mathrm{MHz}$ ), which are seen from graphs are given by parasitic properties of the designed PCB and by bandwidth limitations of the used active elements. That actually applies for all results in the paper. The obtained values are in good agreement with simulations.

The proposed fractional-order filter provides the electronic control of the pole frequency by changing the values of the transconductances. The frequency tuning was 
tested for five values for FLPF when the order of the filter is 1.5 and $Q=0.7$. Obtained magnitude and phase responses of the measurements (solid lines) are compared with simulations (dashed lines) in Fig. 5(a)-Fig. 5(b). The calculated values of the used passive elements are stated in Table IV.

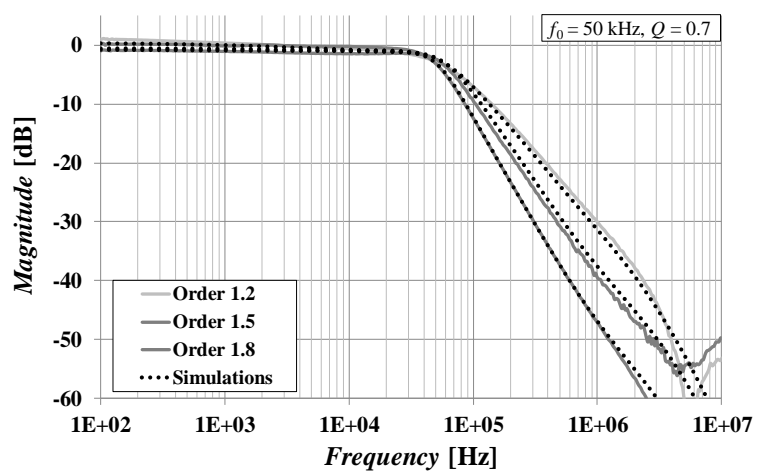

(a)

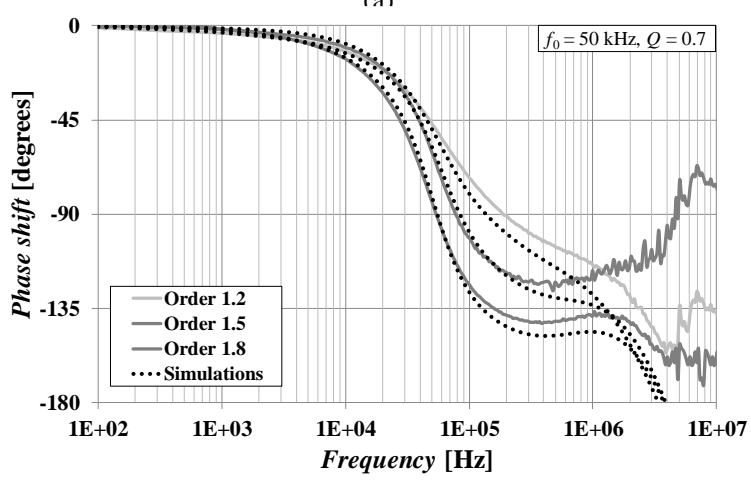

(b)

Fig. 4. Demonstration of the measurement and simulations results of the designed FLPF when changing the order, for the $f_{0}=50 \mathrm{kHz}, \mathrm{Q}=0.7$ : a) magnitude; b) phase shift.

TABLE IV. USED VALUES OF THE FILTER PARAMETERS FOR POLE FREQUENCY CONTROL

\begin{tabular}{|c|c|c|c|c|c|}
\hline $\begin{array}{c}\text { Theoretical values } \\
\text { of the } \boldsymbol{f}_{\mathbf{0}}[\mathrm{kHz}]\end{array}$ & 5 & 10 & 25 & 50 & 150 \\
\hline $\boldsymbol{C}_{\boldsymbol{\alpha}}\left[\boldsymbol{\mu} \mathbf{F s} \mathbf{s}^{\boldsymbol{\alpha}-1}\right]$ & \multicolumn{5}{|c|}{1.7} \\
\hline $\boldsymbol{C}_{\mathbf{2}}[\mathbf{n F}]$ & \multicolumn{5}{|c|}{10} \\
\hline $\boldsymbol{R}_{\boldsymbol{1}}=\mathbf{1} / \boldsymbol{g}_{\boldsymbol{m} \boldsymbol{1}}[\boldsymbol{\Omega}]$ & 1062 & 531 & 266 & 133 & 89 \\
\hline $\boldsymbol{R}_{\boldsymbol{2}}=\mathbf{1} / \boldsymbol{g}_{\boldsymbol{m} \boldsymbol{2}}[\mathbf{\Omega}]$ & 1390 & 695 & 348 & 174 & 116 \\
\hline
\end{tabular}

The obtained values of the pole frequencies from measurements are the following: $3.9 \mathrm{kHz}, 8.9 \mathrm{kHz}$, $22.3 \mathrm{kHz}, 54.7 \mathrm{kHz}$ and $149.8 \mathrm{kHz}$. The values of the pole frequencies from simulations are: $4.4 \mathrm{kHz}, 10.1 \mathrm{kHz}$, $24.5 \mathrm{kHz}, 58.1 \mathrm{kHz}$ and $140.5 \mathrm{kHz}$. The differences are given by inaccuracies of the passive elements as already discussed.

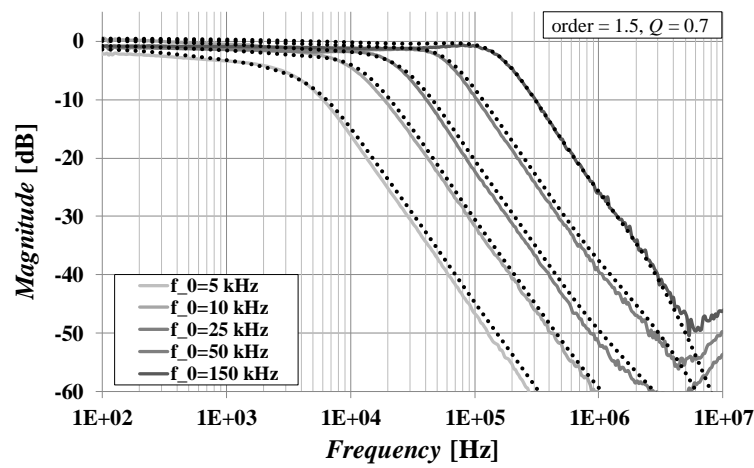

(a)

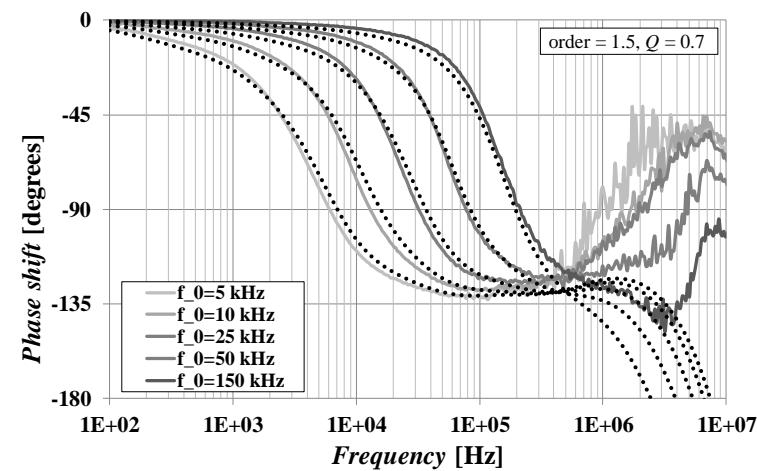

(b)

Fig. 5. Measurement vs. simulations results of the designed FLPF in case of frequency when the order was set to 1.5 and $Q=0.7$ : a) magnitude responses; b) phase shift.

From measurement results can be seen that for $f_{0}=$ $150 \mathrm{kHz}$, the value of the quality factor is slightly bigger than 0.7 . The results are affected by small values of the $1 / g_{\mathrm{m}^{-}}$ $\mathrm{s}$ of the BOTA elements in this particular case. The observed pass-band attenuation of magnitude response for $f_{0}=5 \mathrm{kHz}$ is caused by limited frequency range of the used approximation of the fractional-order capacitor.

The quality factor control of the designed filter is possible by changing the value of the current gain $B_{\mathrm{Q}}$ of the DACA element. The tunability of the quality factor was carried out for four values when we choose the $f_{0}=10 \mathrm{kHz}$ and order of the filter 1.8. The used values of the filter parameters are summarized in Table $\mathrm{V}$. The magnitude and phase responses are demonstrated in Fig. 6.

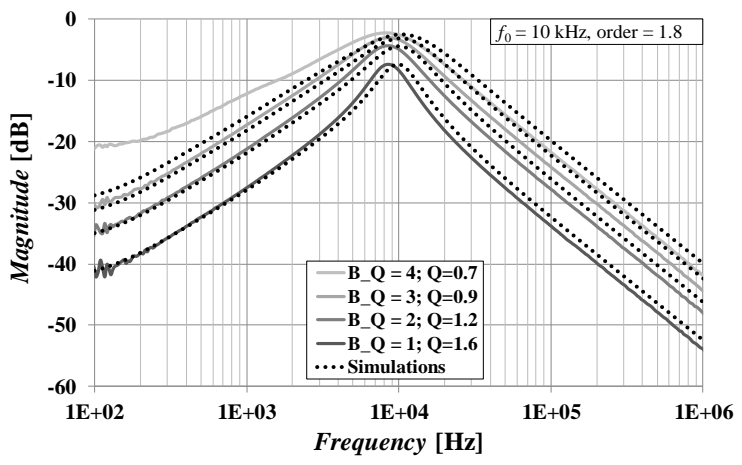

(a)

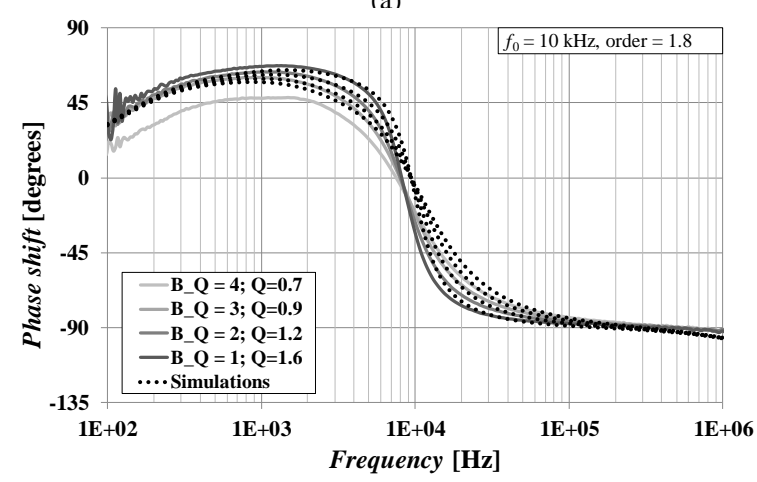

(b)

Fig. 6. Demonstration of the quality factor control of the FBPF for four values of current gain $B_{\mathrm{Q}}$ when the $f_{0}=10 \mathrm{kHz}$ and order 1.8 Measurement vs. simulations: a) magnitude; b) phase shift.

From magnitude responses can be seen that the fractionalorder band-pass function has asymmetrical slopes of attenuation. Below the center frequency is the slope of attenuation $20 \alpha \mathrm{dB} /$ decade and above the center 
frequency is the slope $20 \mathrm{~dB} /$ decade. This is caused by selection of the $C_{1}$ as FOE and particular form of transfer function (2).

TABLE V. QUALITY FACTOR CONTROL.

\begin{tabular}{|c|c|c|c|c|}
\hline Theoretical values of $\boldsymbol{Q}$ & 0.7 & 0.9 & 1.2 & 1.6 \\
\hline $\boldsymbol{C}_{\boldsymbol{\alpha}}\left[\boldsymbol{\mu} \mathbf{F s}^{\boldsymbol{\alpha}-1}\right]$ & \multicolumn{5}{|c|}{0.062} \\
\hline $\boldsymbol{C}_{\mathbf{2}}[\mathbf{n F}]$ & \multicolumn{5}{|c|}{712} \\
\hline $\boldsymbol{R}_{\boldsymbol{1}}=\mathbf{1} / \boldsymbol{g}_{\boldsymbol{m} \boldsymbol{I}}[\mathbf{\Omega}]$ & \multicolumn{5}{|c|}{520} \\
\hline $\boldsymbol{R}_{\boldsymbol{2}}=\mathbf{1} / \boldsymbol{g}_{\boldsymbol{m} \mathbf{2}}[\mathbf{\Omega}]$ & \multicolumn{5}{|c|}{1} \\
\hline $\boldsymbol{B}_{\mathbf{Q}}$ & 4 & 3 & 2 & 1 \\
\hline
\end{tabular}

The obtained values of the quality factor from measurements are: $0.69,0.9,1.14$, and 1.85 . The values of the quality factor from simulations are following: 0.72 , $0.87,1.13$ and 1.64. The obtained values of the quality factor by experimental measurement are in good agreement with results from simulations. From graphs it is obvious that results obtained by measurement are frequency shifted. The frequency shift is caused by inaccurate values of the transconductances. It is also seen that for $B_{Q}=4(Q=0.7)$, bigger differences at low frequency stop band are more significant. This differences are caused mainly by inaccuracy of passive parts and current gain of the $B_{\mathrm{Q}}$ as mentioned above.

\section{CONCLUSIONS}

The reconfigurable frequency filter containing the FOE is presented in this paper. The fractional-order filter provides electronic reconfigurability between LP, HP, BP and BR transfer functions without any reconnection in the filter topology. The circuit provides beneficial ability of the electronic control of the pole frequency and quality factor. The verification of the filter features was performed using simulation with behavioural models and also by measurement with real devices. The correct function of the proposed filter is supported by obtained measured results, which are discussed in the graphs. The filter was tested for three values of the order $(1.2,1.5,1.8)$, obtained values from measurements were $1.19,1.52$ and 1.79 . The pole frequency tuning was tested for five values of $f_{0}(5 \mathrm{kHz}, 10 \mathrm{kHz}$, $25 \mathrm{kHz}, 50 \mathrm{kHz}$ and $150 \mathrm{kHz}$ ), values obtained from measurements were $3.9 \mathrm{kHz}, 8.9 \mathrm{kHz}, 22.3 \mathrm{kHz}, 54.7 \mathrm{kHz}$ and $149.8 \mathrm{kHz}$. The quality factor control was tested for four values $(0.7,0.9,1.2$ and 1.6), obtained values of $Q$ were $0.69,0.9,1.14$ and 1.85 .

\section{REFERENCES}

[1] A. S. Ali, A. G. Radwan, A. M. Soliman, "Fractional order butterworth filter: active and passive realizations", IEEE Journal on Emerging and Selected Topics in Circuits and Systems, vol. 3, no. 3, pp. 346-354, 2013. DOI: 10.1109/JETCAS.2013.2266753.

[2] S. Das, Functional fractional calculus, Second edition. Berlin: Springer, 2011. DOI: 10.1007/978-3-642-20545-3.

[3] T. J. Freeborn, "Comparison of $(1+\alpha)$ fractional-order transfer functions to approximate lowpass butterworth magnitude responses", Circuits, Systems, and Signal Processing, vol. 35, no. 6, pp. 19832002, 2016. DOI: 10.1007/s00034-015-0226-y.

[4] B. Maundy, A. S. Elwakil, T. J. Freeborn, "On the practical realization of higher-order filters with fractional stepping", Signal Processing, vol. 91, no. 3, pp. 484-491, 2011. DOI: 10.1016/j.sigpro.2010.06.018.

[5] A. S. Elwakil, "Fractional-order circuits and systems: An emerging interdisciplinary research area", IEEE Circuits and Systems Magazine, vol. 10, pp. 40-50, 2010. DOI:
10.1109/MCAS.2010.938637.

[6] T. J. Freeborn, B. Maundy, A. S. Elwakil, "Approximated fractional order Chebyshev lowpass filters", Mathematical Problems in Engineering, vol. 2015, pp. 1-7, 2015. DOI: 10.1007/s00034-015$0222-2$.

[7] J. Koton, J. Jerabek, N. Herencsar, D. Kubanek, "Current conveyors in current-mode circuits approximating fractional-order low-pass filter", in Proc. European Conf. Circuit Theory and Design (ECCTD 2017), 2017, pp. 1-4. DOI: 10.1109/ECCTD.2017.8093277.

[8] G. Tsirimokou, C. Psychalinos, A. S. Elwakil, "Fractional-order electronically controlled generalized filters", International Journal of Circuit Theory and Applications, vol. 45, no. 5, pp. 595-612, 2017. DOI: $10.1002 /$ cta.2250.

[9] T. J. Freeborn, A. Elwakil, B. Maundy, "Electrode location impact on cole-impedance parameters using magnitude-only measurements", in 2016 IEEE 59th Int. Midwest Symposium on Circuits and Systems (MWSCAS 2016), 2016, pp. 1-4. DOI: 10.1109/MWSCAS.2016.7869945.

[10] I. Podlubny, I. Petras, B. M. Vinagre, P. O'Leary, L. Dorcak, "Analogue realizations of fractional-order controllers", Nonlinear Dynamics, vol. 29, no. 1/4, pp. 281-296, 2002. DOI: 10.1023/A:1016556604320.

[11] P. Ahmadi, B. Maundy, A. S. Elwakil, L. Belostotski, "High-quality factor asymmetric-slope band-pass filters: a fractional-order capacitor approach", IET Circuits, Devices, vol. 6, no. 3, pp. 187-197, 2012. DOI: 10.1049/iet-cds.2011.0239.

[12] G. Tsirimokou, S. Koumousi, C. Psychalinos, "Design of fractionalorder filters using current feedback operational amplifiers", Journal of Engineering Science \& Technology Review, vol. 9, pp. 77-81, 2016. DOI: 10.25103/jestr.094.12.

[13] J. Dvorak, L. Langhammer, J. Jerabek, J. Koton, R. Sotner, J. Polak, "Synthesis and analysis of electronically adjustable fractional-order low-pass filter", Journal of Circuits, Systems and Computers, vol. 27, no. 02, pp. 1-18, 2018. DOI: 10.1142/S0218126618500329.

[14] G. Tsirimokou, R. Sotner, J. Jerabek, J. Koton, C. Psychalinos, "Programmable analog array of fractional-order filters with CFOAs", in Proc. 40th Int. Conf. Telecommunications and Signal Processing (TSP 2017), Barcelona, Spain, 2017, pp. 706-709. DOI: 10.1109/TSP.2017.8076079.

[15] D. Kubanek, T. Freeborn, " $(1+\alpha)$ Fractional-order transfer functions to approximate low-pass magnitude responses with arbitrary quality factor", AEU - International Journal of Electronics and Communications, vol. 83, pp. 570-578, 2018. DOI: $10.1016 /$ j.aeue.2017.04.031.

[16] R. Caponetto, S. Graziani, F. L. Pappalardo, F. Sapuppo, "Experimental characterization of ionic polymer metal composite as a novel fractional order element", Advances in Mathematical Physics, vol. 2013, pp. 1-10, 2013. DOI: 10.1155/2013/953695.

[17] M. Sivarama Krishna, S. Das, K. Biswas, B. Goswami, "Fabrication of a fractional order capacitor with desired specifications: a study on process identification and characterization", IEEE Trans. Electron Devices, vol. 58, no. 11, pp. 4067-4073, 2011. DOI: 10.1109/TED.2011.2166763.

[18] T. C. Haba, G. L. Loum, G. Ablart, "An analytical expression for the input impedance of a fractal tree obtained by a microelectronical process and experimental measurements of its non-integral dimension", Chaos, Solitons, vol. 33, no. 2, pp. 364-373, 2007. DOI: 10.1016/j.chaos.2006.01.123.

[19] M. Sugi, Y. Hirano, Y. F. Miura, K. Saito, "Simulation of fractal immitance by analog circuits: an approach to the optimized circuits", IEICE Trans. Fundam. Electron. Commun. Comput. Sci., vol. E82, pp. 1627-1634, 1999.

[20] L. Langhammer, J. Jerabek, J. Polak, D. Panek, “A single-ended and fully-differential universal current-mode frequency filter with $\mathrm{MO}-\mathrm{CF}$ and DACA elements", Advances in Electrical and Computer Engineering, vol. 16, no. 3, pp. 43-48, 2016. DOI: 10.4316/AECE.2016.03007.

[21] J. Jerabek, J. Koton, R. Sotner, K. Vrba, "Adjustable band-pass filter with current active elements: two fully-differential and single-ended solutions", Analog Integrated Circuits and Signal Processing, vol. 74, no. 1, pp. 129-139, 2013. DOI: 10.1007/s10470-012-9942-4.

[22] J. Jerabek, K. Vrba, "SIMO type low-input and high-output impedance current-mode universal filter employing three universal current conveyors", AEU - International Journal of Electronics and Communications, vol. 64, no. 6, pp. 588-593, 2010. DOI: 10.1016/j.aeue.2009.03.002.

[23] EL2082 (Elantec), Current-mode multiplier (datasheet). 1996. 